\section{CASE OF LYMPHATIC LEUKEMIA}

$$
\begin{aligned}
& \text { H. H. HAZEN, M.D. } \\
& \text { WASHINGTON, D. c. }
\end{aligned}
$$

On account of the marked blood picture the following case of lymphatic leukemia seems worth reporting:

Patient.-M. D., aged 60, Irish, a watchman. The family and past history are both unimportant. The patient denied any venereal disease and had never used alcohol. He had always been a strong, healthy, hard-working man.

Present Illness.-During the summer of 1903 he noticed enlarged glands in the neck, axilla and groins, together with slight weakness. He had been unsuccessfully treated by several physicians. He first came under observation Oct. 28, 1904, complaining of general weakness, epistaxis and enlarged glands. He was put on potassium iodid, and in two weeks the glands had become smaller and softer; they soon regained their usual large size, however. The probable diagnosis of leukemia was made and the patient was put on Fowler's solu. tion, which did not help him.

Examination.-Late in November $\mathrm{I}$ saw the patient. $\mathrm{He}$ was a well-nourished man, with skin a trifle bronzed, lips and mucous membrane extremely pale. Lungs and heart were normal; abdomen was distended with fluid; the liver was not palpable, but the spleen extended a full hand's breadth below the costal margin. In the anterior triangles of the neck there were enlarged glands, some being as much as $6 \mathrm{~cm}$. long. They were discrete and very hard; the axillary and inguinal glands were also markedly enlarged. From neither the history nor examination was there any evidence of involvement of the mediastinal glands. The legs were slightly edematous; the urine was absolutely normal. One month later a blood examination was made, with the following results: Hemoglobin, 20 per cent.; red cells, 960,000; white cells, 250,000. A smear showed the red cells to be normal in appearance; no nucleated reds and no megaloblasts were seen. The predominating white blood cells were small mononuclear non-granular cells, typical lymphocytes. Only two polymorphonuclears were seen. There were no eosinophiles, no mast-cells, no large mononuclears, and no myelocytes.

Course of Disease.-While I did not see the patient again, I am informed by his physician that he grew steadily weaker, that he had severe attacks of epistaxis and that his liver became enlarged. Death took place on Feb. 12, 1905. No autopsy was permitted.

1204 Eighteenth Street.

\section{TUBERCULOSIS EXHIBIT AND CABINET}

\section{FRANK B. WYNN, M.D.}

$$
\text { INDIANAPOLIS }
$$

This descriptive article is published as a means of answering numerous inquiries concerning the tuberculosis exhibit shown at the recent American Medical Association session in the name of the Indianapolis Medical Society. As will be seen from the picture, the exbibit is housed in a handsome and substantial cabinet, consisting of an upper show ease in which are placed models of pavilions, shacks, tents and devices used in the treatment of tuberculosis. Appended to each of the models are brief data as to materials and cost of construction. At one end of the cabinet is a flashlight transparency, which announces that with the lapse of every three seconds another victim has been claimed by tuberculosis.

The lower half of the case consists of two drawers, 10 by 14 by 22 inches in size, opening on opposite sides of the case. This enables several persons to be examining the contents of the drawers at the same time. In these drawers are anchored (similar to any index file) a hundred or more heavy cards on which are photographs, cartoons and diagrams with appropriate descriptions, statistical data, mottoes, sanitary dicta, etc., relating to the whole problem of tuberculosis.

Signs in the glass case call attention to the drawers below where the observer is invited to learn the story of the great white plague. A smaller cabinet embodying the same principles can be manufactured for at least half the price of the larger one.

Marvelous strides have been made in preventive medicine during the past two decades through the usual health board propaganda-bulletins, circulars, popular lectures and the like. More recently these means are being supplemented by exhibits relating to public health problems-notably tuberculosis. While they represent the most efficient means thus far employed to enlighten the public on sanitary questions, they are open to the serious objection of cumbersomeness and expense in maintenance. They are presented for a few days in the community and perhaps never again. Such spasmodic efforts can not bear the good fruit that would arise from means which could keep the question constantly before the people.

\section{DISADVANTAGES OF PAST METHODS}

As a concrete example take the exhibit of the New York Charities Organization. It is the most complete and comprehensive that has been devised in this country. Installed for a few days now in one part and now in another part of New York City, it has been of incalculable value in teaching, especially the lower classes, the story of tuberculosis in all its aspects. But however excellent, a fair criticism of the practicability of this exhibit (and similar ones) may be made on the following grounds:

1. Its primary cost, which must have been from $\$ 1,200$ to $\$ 1,500$.

2. The cost of housing - a large room being necessary.

3. Expense of moving, installing and proper supervision. (The cost of its presentation at the Atlantic City meeting of the American Medical Association was over a hundred dollars.)

4. The short period of time during which it is maintained in any given place.

\section{ADVANTAGES OF THIS EXHIBIT}

To overcome such objections as the foregoing the Scientific Exhibit Committee of the American Medical Association has for the past two years been endeavoring to interest sanitarians in developing a compact but comprehensive tuberculosis exhibit. Five were offered at the last meeting, each having distinct points of merit. The one herein described does not fulfill all requirements, but $I$ believe has much to commend it. The advantages may be summarized as follows:

1. Compactness, neatness and stability: The cabinet takes up but little room and can stand with safety in any public building where crowds congregate.

2. Completeness: Although compact, it can be made to contain as much as the large exhibits-all that is necessary for the instruction of the public.

3. It requires no supervision, but tells its own story graphically.

4. Cost: If manufactured in large numbers, they could be sold at a figure sufficiently low to enable health boards to place them in railway stations, court-houses, public libraries and like places.

5. The continuity of effort would bring home to the people the lessons of the tuberculosis problem every day of the year.

6 . The same cabinet might be used as occasion required for instruction on other sanitary matters. 


\section{PROBLFM OF PRODUCTION}

To the many inquiries which have been made as to the cost of these caljinets and where they may be obtained, no satisfactory answer can be made. 'Two large concerns have made overtures looking to their manufacture. In order to secure the widest possible educationai effect, it is desirable that the exhibits be sold almost at rost to insure their general use. Is it practicable to attain this end? Why should not the Board of 'Trustees of the Association, the Scientific Exhibit ('ommittee on other recularly constituted representative undertake the supervision of this unlertaking? Jet them ascertain through experts the lowest figure at which these cabinets, equipped, can be made. Then secure an agreement from some reputable firm to market them at this price.

The Association's endorsement would insure large sale. Let the manufacturer pay the Association a roy. alty to cover the expense of proper supervision of the (lata that go into the cabinets. These would need to bo varied to suit localities and states. Such supervision would insure the introduction of such matter only as

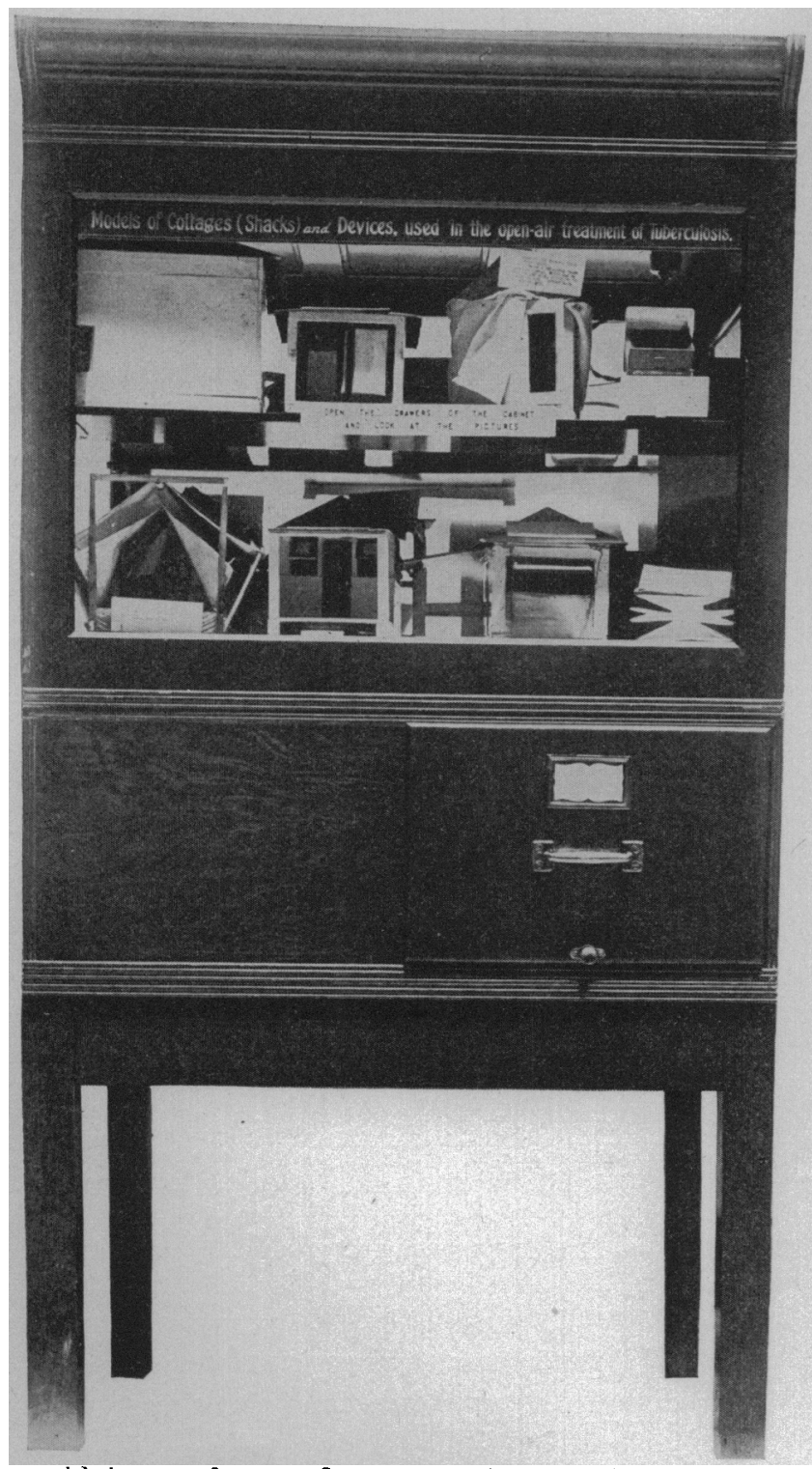

would be prudent and sane; sufficiently instructive to the lay inind on tuberculosis and other sanitary questions, but so tempered as not to excite ridicule or unnecessarily alarm the people on such matters. It would offer the Association an opportunity to render most effective cooperative aid to health authorities and, therefore, would prove of grcat service in the march of preventive medicine-a field in which the Association, as an organization, has as ret done but little.

311 Newton Claypool Building.

\section{A CASE OF SYPHILIS IRESEMBIING PITYRIA- SIS RUBRA PILARIS \\ HOWARD FOX, M.D. \\ NEW YORL CITY}

The following case of miliary papular syphilis is of interest on account of its very close resemblance to the papular stage of pitrriasis rubra pilaris. When seen in August, 1908, at the Vanderbilt Clinic, the patient, a widow of 30 , presented a general eruption of the face, trunk and extremities. This consisted, for the most

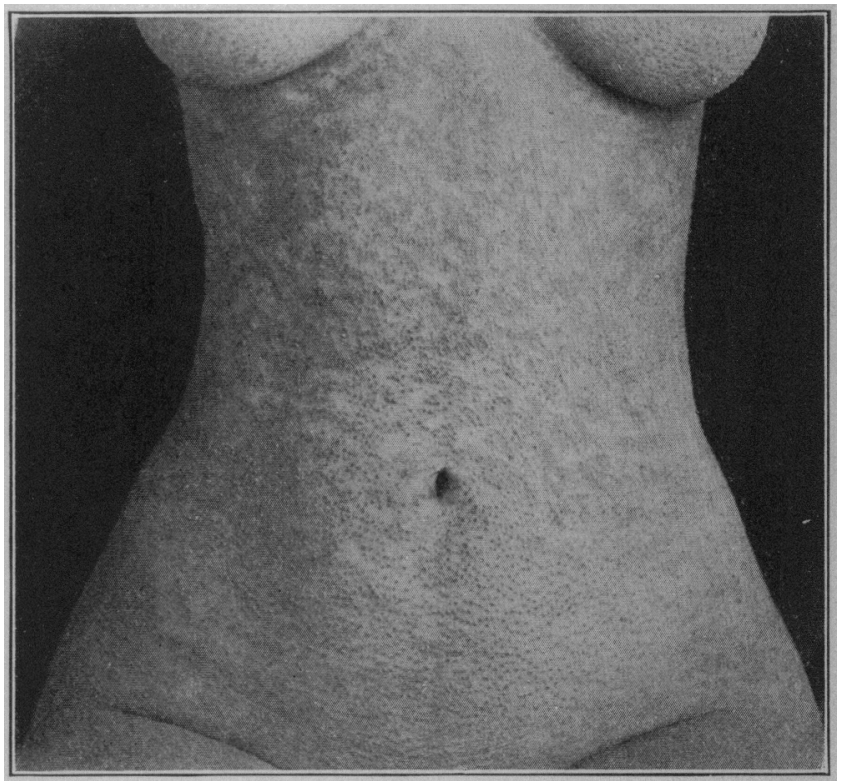

A case of miliary papular syphilis in which the eruption simulated pityriasis rubra pilaris.

part, of small, conical, pin-head papules, capped with horny scales. 'There was no tendency for the lesions to become confiuent and there were no signs of itching. On the face there were erythematous and scaly lesions that might have occurred with either of due diseases in question. There was no history of any genital sore, no glandular enlargement and no lesions of the mouth. The palms were thickened and scaly, but did not present the appearance characteristic of the early palmar syphilide. While the eruption simulated a pityriasis rubra pilaris very closely, it was noticed that there was a slight tendency of the papules to follicular grouping so characteristic of miliary papular syphilide. Further, the appearance of the backs of the phalanges generally noted in pityriasis rubra pilaris was absent.

When the case was first seen I had not begun to work with the Wassermann test, and a clinical diagnosis alone was possible. To show the great difficulty in diagnosis it may be said that a distinguished dermatolowist of the city pronounced the case to be unquestionably one of pityriasis rubra pilaris. The patient was kept under observation for two weeks, at the end of which time the lesions began to show a tendency to become papulosquamous, and she was then put on antisyphilitic treatment; within a month the greater part, of the eruption had disappeared. The patient then became somewhat irregular in attendance at the clinic, 